\title{
Distinguishing well-differentiated hepatocellular carcinoma from benign liver by the physical features of fine-needle aspirates
}

\author{
Grace CH Yang, Guang-Yu Yang and Liang-Che Tao* \\ Department of Pathology, New York University School of Medicine, New York, NY, USA
}

\begin{abstract}
Distinguishing well-differentiated hepatocellular carcinoma (HCC) from benign hepatic lesions is challenging for pathologists in limited diagnostic material such as needle-core tissue biopsy and fine-needle aspiration (FNA) biopsy. The objective of this study is to test a hypothesis that the fortification of liver by reticulin along single cell plates should protect benign hepatic lesions from breakdown by the force of aspiration and smearing, whereas the decreased reticulin in well-differentiated HCC would result in finely granular FNA smear. The study involved FNA biopsies of 67 cases of well-differentiated HCC and 109 cases of benign hepatic lesions, including cirrhosis (22), liver cell adenoma (8), steatosis (7), focal nodular hyperplasia (6), liver with cholestasis (6), and unremarkable liver sampled from nodular hepatic lesions consistent with the regenerative nodules (60). A slide with the most sample from each case by gross inspection was mixed together. Two observers blinded to the diagnoses were asked to separate the slides into two groups based on smear characteristics by gross inspection. Fragments of rigid fine-needle cores was present in 109 out of 109 cases of benign hepatic lesions but absent in 61 out of 67 cases of well-differentiated HCC, which presented as finely granular smears. The difference is statistically significant. $\left(P<0.001, \mathrm{df}=1, \chi^{2}=149.3\right)$. Using the physical characteristic of liver aspirates as the screening test for malignancy, the sensitivity is $91 \%$, specificity is $100 \%$, positive predictive value is $100 \%$, negative predictive value is $94.8 \%$, and efficiency is $96.6 \%$. In conclusion, the smear characteristics of liver samples in FNA biopsy correlate to their reticulin status on histology. This physical characteristic can be used as the first clue to distinguish malignant and benign liver aspirates prior to microscopic examination.
\end{abstract}

Modern Pathology (2004) 17, 798-802, advance online publication, 26 March 2004; doi:10.1038/modpathol.3800121

Keywords: fine-needle aspiration biopsy; hepatocellular carcinoma; cirrhosis; liver cell adenoma; focal nodular hyperplasia; macroregenerative nodule

Improved imaging techniques have led to increasing detection of hepatic nodules, which are frequently biopsied by radiologists. In limited diagnostic samples such as needle-core tissue biopsy or fine-needle aspiration (FNA) biopsy, the diagnostic difficulties lie at both ends of the malignant spectrum, that is, the distinction of moderately to poorly differentiated hepatocellular carcinoma (HCC) from adenocarcinomas $^{1-3}$ and the distinction of well-differentiated HCC from cirrhosis, macroregenerative nodules, and other

Correspondence: Dr GCH Yang, MD, Cytopathology Laboratory, NB-4S-17, NYU Medical Center, 462 First Ave, New York, NY 10016, USA.

E-mail: grace.yang@nyu.edu

*Professor Emeritus of Pathology, Indiana University School of Medicine.

None of the authors has any financial affiliation in the commercial products used in this study.

Received 22 November 2003; revised 23 December 2003; accepted 26 December 2003; published online 26 March 2004 benign hepatic processes. ${ }^{3-7}$ With the use of coordinated cytokeratins, ${ }^{8,9}$ and Hepar-10-12 immunostains, the problem of the former distinction is more or less solved. However, the distinction of welldifferentiated HCC from benign liver nodules is still considered as difficult for the reasons best summarized by Ferrell ${ }^{13,14}$ (a) the absence of portal-central vein architectural relationships, (b) the disruption of architecture by the smearing, (c) the absence of surrounding normal hepatocytes to be used as a control to appreciate the increased nuclear density of small cell change, and (d) large cell change within a cirrhotic nodule that may resemble well-differentiated HCC arising in cirrhotic nodule. Based on 49 cases of HCC, Noguchi et al ${ }^{15}$ reported the diagnostic rates of FNA biopsy for well-differentiated HCC as $90.5 \%$, compared to $100 \%$ for moderately and poorly differentiated HCC.

The difficulty in distinguishing well-differentiated HCC from benign hepatic processes in limited 
diagnostic samples is reflected by various ancillary studies seeking a magic marker to solve this problem. In 1997, Tanigawa et $a l^{16}$ reported that CD34 immunostaining in benign liver tissue was confined to vessels in the portal tract and to a few periportal sinusoids. In HCC, however, sinusoid vessels reacted intensively with anti-CD34. Tumor angiogenesis assessed by anti-CD34 correlated with the outcome of patients with HCC. However, de Boer et $a 1^{17}$ in 2000 reported that although diffuse CD34 positivity was present in HCC, moderate CD34 staining was also present in occasional benign processes including focal nodular hyperplasia, cirrhosis, hepatitis, and macroregenerative nodules. In 1996, Nouso et $a l^{18}$ reporting strong activity of telomerase in HCC, suggested that telomerase assay be used as a tool for the differential diagnosis of HCC. Nakashio et $a l^{19}$ confirmed this finding. In 2001, Miskad et $a l^{20}$ reported that PIVKA-II (proteininduced vitamin $\mathrm{K}$ antagonist II) was expressed in small and well-differentiated HCC cells, but was absent in adenomatous hyperplasia, thus providing another promising antibody to distinguish welldifferentiated HCC from benign hepatic processes. In addition, DNA contents were found to be useful in the distinction between liver cell adenoma, HCC, and regenerative nodule. ${ }^{21}$

An old histochemical stain, Gomori silver stain for the reticulin fibers, has gained a new appreciation in solving the diagnostic problem of welldifferentiated HCC. Reticulin stain is now regarded as more dependable and consistent than any of the antibodies, enzymes, or DNA contents in the distinction of well-differentiated HCC from benign hepatic lesions. Reticulin wraps along the single plate architecture in all benign hepatic lesions and is decreased or absent in well-differentiated HCC. As early as 1993, Ferrell et $a l^{22}$ stated that 'reduced or absence of an intact reticulin pattern is an important criterion for malignancy' in their proposal for standardized criteria for the diagnosis of benign, borderline, and malignant hepatocellular lesions arising in chronic advanced liver disease. In the previous year, they reported that loss of reticulin was usually very helpful in differentiating macroregenerative nodules from small HCC in cirrhotic liver. ${ }^{23}$ In her 2000 short course ${ }^{13}$ Ferrell listed the reticulin status of hepatocellular nodules in both cirrhotic and noncirrhotic livers in two tables. She reported a normal reticulin in focal nodular hyperplasia, liver cell adenoma (may be slightly decreased), nodular regenerative hyperplasia in noncirrhotic livers, and in cirrhotic livers, an intact reticulin in macroregenerative nodules. She noted the common and extensive decrease of reticulin in HCC. In 1997, Bergman et $a l^{24}$ analyzed the reticulin-staining pattern in cell blocks prepared from FNA biopsies using semiquantitative grading of 16 HCC and 16 benign hepatic nodules. They concluded that the reticulin stain was particularly useful in distinguishing HCC from benign hepatic processes. In 1999, de Boer et $a l^{25}$ reported that eight of nine HCCs, which were indeterminate at initial diagnosis due to bland cytology, showed reduced or absent reticulin framework in cell block. In review, the sensitivity of diagnosing HCC improved from 77 to $98 \%$ using that criteria. They concluded that reticulin stain in cell block is most valuable. They also reported that reticulin stain consistently distinguished HCC from benign lesions in contrast to CD34 immunostain. ${ }^{17}$ The reticulin framework that holds the benign liver tissue fragments together and decreased reticulin in well-differentiated HCC were illustrated in the direct FNA smears by Gagliano. ${ }^{26}$

The objective of this study is to test a hypothesis that the reticulin fiber framework along single cell plates in benign hepatic lesions should be difficult to break apart by the physical force of aspiration and smearing, while the decreased reticulin in welldifferentiated HCC should result in a breakdown of the aspiration sample into fine granular appearing smears.

\section{Materials and methods}

The FNA biopsy samples were obtained by radiologists via a 10-in long 22-gauge needle under ultrasound guidance. A cytotechnologist was present on-site to make Swedish-styled oval smears on clear microscopic slides, which were then air-dried. As taught by Torsten Löwhagen of Karolinska Institute at Sweden, the aspirate was deposited near the frosted end of the microscopic slide. Holding the frosted end with the left thumb and index finger and the rest of the slide supported by the remaining fingers, the slide remained horizontal and motionless. Another microscopic slide was held by the right thumb and index finger at right angle to the bottom slide, the top slide was placed on the bottom slide at $45^{\circ}$ angle at a distance so that when the top slide was lowered to $0^{\circ}$ angle, the majority, but not all, of the sample will be touched by the far end of top slide, creating a circle, which then gently smeared, forming 'head, body, and tail'. ${ }^{27}$ At least one smear from each pass was stained with rapid Romanovsky stain (Mecedes Medical, Sarasota, FL, USA) for the assessment of sample adequacy . The remaining air-dried smears were brought back to the laboratory for Ultrafast Papanicolaou stain ${ }^{28}$ (Richard Allan Scientific, Kalamazoo, MI, USA). Every FNA biopsy also has a portion of the sample fixed directly in CytoRich Red for the preparation of cell block. ${ }^{29}$

A computer search from 1996 to 2003 at New York University Medical Center identified FNA biopsies of 67 cases of well-differentiated HCC and 109 cases of benign hepatic lesions. Well-differentiated HCC is defined by the presence of malignant cells that resemble normal hepatocytes with minimal nuclear atypia and the absence of naked nuclei in the smears, that is, the plasma membrane of the neoplastic hepatocytes can survive the force of 
smearing. The benign hepatic lesions included 22 cases of cirrhosis, eight cases of liver cell adenoma, seven cases of steatosis, six cases of focal nodular hyperplasia, six cases of liver with cholestasis, and 60 cases of unremarkable liver sampled from nodular hepatic lesions consistent with regenerative nodules. All cases have an accompanying cell block with reticulin stain. All the smears for a given case were evaluated grossly. It was found that there was no variability in the physical characteristics of the sample for each case, only the quantity of the sample on each slide varied. The slide with the most sample was selected and mixed together. Two observers, blinded to the diagnoses, were asked to separate the slides into two groups based on smear characteristics by gross inspection. The data were analyzed by $\chi^{2}$-test.

\section{Results}

As shown in Table 1, fragments of rigid fine-needle cores or very large tissue fragments were present in

Table 1 FNA smear characteristics and the final diagnosis

\begin{tabular}{lccr}
\hline & Finely granular & Rigid cores & \\
\hline HCC & 61 & 6 & 67 \\
Benign & 0 & 109 & 109 \\
& 61 & 115 & 176 \\
\hline
\end{tabular}

HCC, well-differentiated hepatocellular carcinoma.
109 out of 109 cases of benign hepatic lesions but absent in 61 out of 67 cases of well-differentiated HCC, which presented as finely granular smears. The difference is statistically significant $(P<0.001$, $\mathrm{df}=1, \chi^{2}=149.3$ ). There were six cases of welldifferentiated HCC presented as rigid tissue fragments. Using physical characteristic of liver aspirates as the screening test for malignancy, the sensitivity is $91 \%$, specificity is $100 \%$, positive predictive value is $100 \%$, negative predictive value is $94.8 \%$, and efficiency is $96.6 \%$. All benign hepatic lesions had intact reticulin along single cell plate, in contrast to the decreased or absent reticulin in well-differentiated HCC.

During on-site assessment, the FNA samples from benign hepatic lesions typically appear as fineneedle cores when deposited on the slide, and would roll with the action of smearing and be difficult to smear (Figure 1a). When crushing force was applied, the fine-needle cores may be broken down into large tissue fragments. The rigidity is attributed to the fortification of the tissue by the intact reticulin along single cell plate architecture in benign hepatic lesions (Figure 1b). In contrast, FNA samples from well-differentiated HCC, most frequently but not always, would appear as a liquid droplet when deposited on the slide (Figure 1c, arrow), which was easily smeared (Figure 1c) because of the decreased reticulin (Figure 1d). The three cases of HCC illustrated here were so welldifferentiated that their malignant nature was not realized until clinical follow-up. ${ }^{30}$
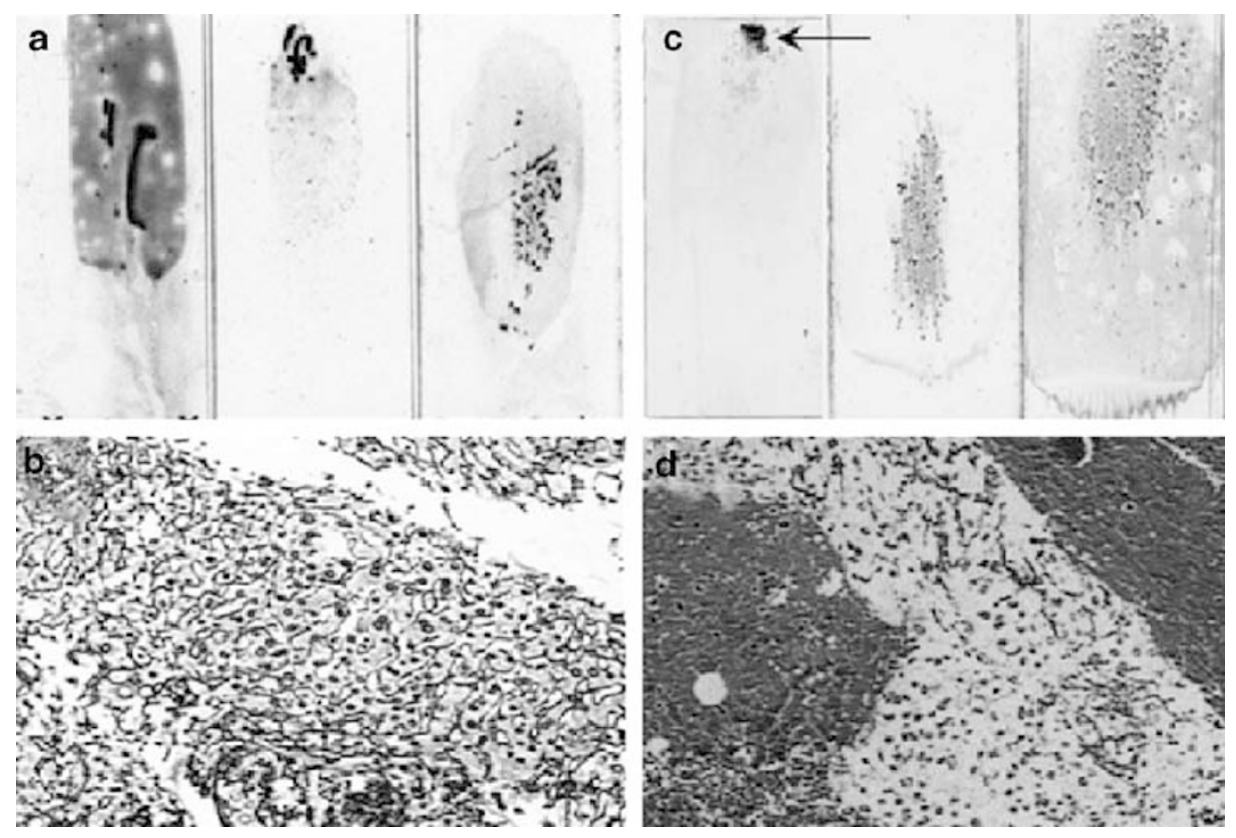

Figure 1 Comparison of benign hepatic lesions (left column) and well-differentiated HCC (right column). (top row): Fine-needle aspiration smears, ultrafast Papanicolaou stain, (bottom row): Cell blocks, reticulin stain. (a) Aspirate of benign hepatic lesions presented as the rigid cores when deposited on the slide and rolled with the smearing (left and center slides). Occasionally, it may be broken down into large tissue fragments when crushing force was used (right slide). (b) Their rigidity is because of the fortification of tissue by reticulin wrapping along single cell plate architecture. (c) The aspirate of well-differentiated HCC, most frequently but not always, presented as liquid droplets (arrow) when deposited on the slide and easily smeared into finely granular smear because of decreased reticulin (d). 


\section{Discussion}

In contrast to needle-core biopsies, the FNA biopsy samples are not immediately fixed in formalin, but instead, are smeared directly onto glass slides, thus offering an opportunity to test the physical characteristics of the liver samples directly. The physical characteristic of liver FNA samples is found to be parallel to the reticulin status in histology, which is used by liver pathologists to distinguish welldifferentiated HCC from various benign hepatic processes.

Not all (91\%) well-differentiated HCC produce granular smears, but when such a finding is present, a benign hepatic process can be excluded. In welldifferentiated HCC, the reticulin framework is reduced or absent; consequently, the force of rapid needle puncture by the aspirator will liquefy the tissue and the force of smearing will yield finely granular smears. The reticulin framework in various benign liver processes such as liver cell adenoma, cirrhosis, macroregenerative nodules, focal nodular hyperplasia, etc is intact, thus the liver aspirate appears as fine-needle cores on the slide and is difficult to be smeared apart. This physical feature will be particularly helpful during on-site assessment for FNA biopsies to guide radiologists to the right nodule, and to recognize HCC that are so welldifferentiated that they did not meet the classic cytologic criteria for HCC. ${ }^{30}$

Another issue is that the interventional radiologists may have selection bias in deciding which type of hepatic lesions to be sampled by needlecore biopsy or FNA biopsy. However, the selection bias has minimal impact in terms of the observation reported. Lastly, we would like to emphasize that the physical characteristics of the liver aspirate are independent of the smearing skill of the operator.

\section{References}

1 Bottles K, Cohen MB, Holly EA, et al. A step-wise logistic-regression analysis of hepatocellular carcinoma-an aspiration biopsy study. Cancer 1988;62: 558-563.

2 Cohen MB, Haber MM, Holly EA, et al. Cytologic criteria to distinguish hepatocellular carcinoma from nonneoplastic liver. Am J Clin Pathol 1991;95: 125-130.

3 Das DK. Cytodiagnosis of hepatocellular carcinoma in fine-needle aspirates of the liver: its differentiation from reactive hepatocytes and metastatic adenocarcinoma. Diagn Cytopathol 1999;21:370-377.

4 Nagato Y, Kondo F, Kondo Y, et al. Histological and morphometrical indicators for a biopsy diagnosis of well-differentiated hepatocellular carcinoma. Hepatology 1991;14:473-478.

5 Wee A, Nilsson B. Highly well differentiated hepatocellular carcinoma and benign hepatocellular lesions. Can they be distinguished on fine needle aspiration biopsy? Acta Cytol 2003;47:16-26.
6 Longchampt E, Patriarche C, Fabre M. Accuracy of cytology vs microbiopsy for the diagnosis of welldifferentiated hepatocellular carcinoma and macroregenerative nodule. Definition of standardized criteria from a study of 100 cases. Acta Cytol 2000;44: 515-523.

7 Takenaka A, Kaji I, Kasugai $\mathrm{H}$, et al. Usefulness of diagnostic criteria for aspiration cytology of hepatocellular carcinoma. Acta Cytol 1999;43:610-616.

8 Wang NP, Zee S, Zarbo RJ, et al. Coordinate expression of cytokeratin-7 and cytokeratin-20 defines unique subsets of carcinomas. Appl Immunohistochemistry 1995;3:99-107.

9 Lau SK, Prakash S, Geller SA, et al. Comparative immunohistochemical profile of hepatocellular carcinoma, cholangiocarcinoma, and metastatic adenocarcinoma. Hum Pathol 2002;33:1175-1181.

10 Wennerberg AE, Nalesnik MA, Coleman WB. Hepatocyte paraffin 1: a monoclonal antibody that reacts with hepatocytes and can be used for differential diagnosis of hepatic tumors. Am J Pathol 1993;143: 1050-1054.

11 Zimmerman RL, Burke MA, Young NA, et al. Diagnostic value of hepatocyte paraffin 1 antibody to discriminate hepatocellular carcinoma from metastatic carcinoma in fine-needle aspiration biopsies of the liver. Cancer (Cancer Cytopathol) 2001;93:288-291.

12 Siddiqui MT, Saboorian MH, Gokaslan ST, et al. Diagnostic utility of the HepPar-1 antibody to differentiate hepatocellular carcinoma from metastatic carcinoma in fine-needle aspiration samples. Cancer (Cancer Cytopathol) 2002;96:49-52.

13 Ferrell L. Liver pathology: cirrhosis, hepatitis, and primary liver problems. Update and diagnostic problems (short course). Mod Pathol 2000;13:679-704.

14 Ljung B, Ferrell L. Fine needle aspiration biopsy of the liver: diagnostic problems. In: Ferrell L (ed). Diagnostic Problems in Liver Pathology. Hanley \& Belfus: Philadelphia, 1994, pp 161-184 (Pathology. State of the Art Reviews; vol 3).

15 Noguchi S, Yamamoto R, Tatsuta M, et al. Cell features and patterns in fine-needle aspirates of hepatocellular carcinoma. Cancer 1986;58:321-328.

16 Tanigawa N, Lu CD, Mitsui T, et al. Quantitation of sinusoid-like vessels in hepatocellular carcinoma: Its clinical and prognostic significance. Hepatology 1997; 26:1216-1223.

17 de Boer WB, Segal A, Frost FA, et al. Can CD34 discriminate between benign and malignant hepatocytic lesions in fine-needle aspirates and thin core biopsies? Cancer (Cancer Cytopathol) 2000;90: 273-278.

18 Nouso K, Urabe Y, Higashi T, et al. Telomerase as a tool for the differential diagnosis of human hepatocellular carcinoma. Cancer 1996;78:232-236.

19 Nakashio R, Kitamoto M, Tahara H, et al. Significance of telomerase activity in the diagnosis of small differentiated hepatocellular carcinoma. Int J Cancer 1997;74:141-147.

20 Miskad UA, Yano Y, Nakaji M, et al. Histological study of PIVKA-II expression in hepatocellular carcinoma and adenomatous hyperplasia. Pathol Int 2001;51: 916-922.

21 Ruschenburg I, Hofmann M, Diab E, et al. Comparison of the DNA content in liver cell adenoma, hepatocellular carcinoma and regenerative nodules. Anticancer Res 2000;20:1861-1864. 
22 Ferrell LD, Crawford JM, Dhillon AP, et al. Proposal for standardized criteria for the diagnosis of benign, borderline, and malignant hepatocellular lesions arising in chronic advanced liver-disease. Am J Surg Pathol 1993;17:1113-1123.

23 Ferrell L, Wright $\mathrm{T}$, Lake J, et al. Incidence and diagnostic features of macroregenerative nodules vs small hepatocellular-carcinoma in cirrhotic livers. Hepatology 1992;16:1372-1381.

24 Bergman S, Graeme-Cook F, Pitman MB. The usefulness of the reticulin stain in the differential diagnosis of liver nodules on fine-needle aspiration biopsy cell block preparations. Mod Pathol 1997;10: 1258-1264.

25 de Boer WB, Segal A, Frost FA, et al. Cytodiagnosis of well differentiated hepatocellular carcinoma: can indeterminate diagnoses be reduced? Cancer (Cancer Cytopathol) 1999;87:270-277.
26 Gagliano EF. Reticulin stain in the fine-needle aspiration differential-diagnosis of liver nodules. (letter). Acta Cytol 1995;39:596-598.

27 Yang GCH, Hoda SA. Combined use of 'Scratch and smear' sampling technique and Ultrafast Papanicolaou stain for intraoperative cytology. Acta Cytol 1997;41: 1315-1318.

28 Yang GCH, Alvarez II. Ultrafast Papanicolaou stain: an alternative preparation for fine-needle aspiration cytology. Acta Cytol 1995;39:55-60.

29 Yang GCH, Wan LS, Papellas J, et al. Compact cell blocks: use for body fluids, fine needle aspirations, and endometrial brush biopsies. Acta Cytol 1998;42:703-706.

30 Yang GCH, Yang GY, Tao LC. Cytologic features and histologic correlations of microacinar and microtrabecular types of well-differentiated hepatocellular carcinoma in fine needle aspiration biopsy. Cancer, (Cancer Cytopathol) 2004;102:27-33. 